Research Article

\title{
Reliability-Based Analysis of Recycled Aggregate Concrete under Carbonation
}

\author{
Flora Faleschini $\mathbb{D}^{1,2}$ Mariano Angelo Zanini ${ }^{10},{ }^{1}$ and Lorenzo Hofer ${ }^{1}{ }^{1}$ \\ ${ }^{1}$ Department of Civil, Environmental and Architectural Engineering, University of Padova, Via Marzolo 9, 35131 Padova, Italy \\ ${ }^{2}$ Department of Industrial Engineering, University of Padova, Via Gradenigo 6, 35131 Padova, Italy \\ Correspondence should be addressed to Flora Faleschini; flora.faleschini@dicea.unipd.it
}

Received 5 February 2018; Accepted 28 June 2018; Published 26 July 2018

Academic Editor: Carlos Chastre

Copyright (C) 2018 Flora Faleschini et al. This is an open access article distributed under the Creative Commons Attribution License, which permits unrestricted use, distribution, and reproduction in any medium, provided the original work is properly cited.

\begin{abstract}
Durability represents a crucial issue for evaluating safety and serviceability of reinforced concrete structures. Many studies have already focused on carbonation-induced corrosion of natural aggregate concrete (NAC) structures, leading to several prediction models to estimate carbonation depth. Less research is devoted instead on recycled aggregate concrete (RAC), about which limited experimental works exist aimed at assessing the carbonation coefficient in accelerated tests. Additionally, deteriorating processes are subject to uncertainty, when defining materials, geometry, and environmental actions during the service life of structures. This work presents a reliability-based analysis of carbonation resistance of RACs, using experimental carbonation coefficients derived from the literature, and applied in the full-probabilistic method prosed in fib Bulletin 34. Results demonstrate how aggregates replacement ratio and $\mathrm{w} / \mathrm{c}$ ratio influence the reliability of RAC carbonation resistance.
\end{abstract}

\section{Introduction}

Reinforced concrete (RC) structures suffer deterioration processes, due to several concurring causes linked to material defects, poor design and workmanship operations, environmental and physical actions, and inadequate maintenance over time. Among the possible deterioration conditions, steel bar corrosion is considered the most dangerous for RC structures. Two primary causes may lead to this phenomenon: carbonation and chloride diffusion. In particular, the former represents one of the most recurrent deterioration mechanisms observed in European structures [1]; furthermore, as carbon dioxide availability in atmosphere is growing in the last 30 years, nowadays this problem becomes extremely topical [2]. The occurrence of damage states such as bar corrosion may decrease significantly structural performance, which has to be considered as a time-dependent variable [3], thus affecting the service life of a structure. At the ultimate limit state (ULS), the global structural capacity of a deteriorated structure may be difficult to be estimated, due to the concomitant loss of bonding action between the reinforcement and concrete and to steel capacity reduction.

Carbonation-induced corrosion is a complex process, which involves several phenomena with different nature at the microscale level (i.e., electrochemical reactions and concrete cracking). The process is divided in two main steps: the first in which concrete cover is subject to carbonation, and the second in which corrosion is effectively triggered. An extensive literature is available concerning both carbonation and corrosion, and empirical formulations; analytical (both deterministic and probabilistic) and numerical models were widely provided by many authors [4-8]. Concerning the nature of the process, most of the influencing parameters are affected by uncertainty, starting from the environmental conditions that govern carbon dioxide diffusion, to material properties.

Even though large literature is available about carbonation modeling of natural aggregate concrete (NAC), less research relates to the study of this mechanism in recycled aggregate concrete (RAC). Particularly, this problem is manly investigated based on experimental observations 
carried out with accelerated carbonation tests [9-12], aimed at estimating the carbon diffusion coefficient. Recycled aggregates (RAs) are characterized by a heterogeneous composition, with cement-bounded aggregates, unbounded aggregates, and particles of clay bricks, glass, asphalt, and other materials. Even when controlled production processes are used (i.e., when high-quality "type A" RAs are produced mainly constituted by concrete only, as defined in $[13,14])$, high amount of old attached mortar might be present, thus influencing RAC performances. It is worth recalling that RA composition affects significantly their performance in concrete, and generally water absorption, aggregate density, and the amount of adhered mortar are fundamental parameters which must be known to assess aggregates quality. Concerning durability under carbonation, it is commonly agreed that when RAs are used, carbonation resistance is worsened, even if some controversial results are also present in the literature. Most of research works reported that carbonation resistance of RAC is slightly inferior to that of NAC, due to the increased porosity resulting from the high quantity of the attached mortar [10, 12, 15]. Increasing carbonation depth was observed when the rate of aggregates substitution increases [16]. Conversely, other researchers found that when recycling rate achieves $100 \%$, carbonation resistance is enhanced [17], even if this conflicting result might be due by other influencing parameters linked to concrete composition.

Current standards and codes generally adopt prescriptive methods to ensure RC structures the required durability. The fib Bulletin 34 [18] has included a fullprobabilistic approach to predict carbonation depth of uncracked concrete, for estimating RC structures service life, implementing a performance-based design approach. Other than the above method, two further levels of approximation are proposed: a partial factor design approach and deemedto-satisfy design approach. Alternatively, the avoidance-ofdeterioration approach can be followed acting on other variables to hinder depassivation occurrence (i.e., when concrete resistance to carbonation is infinite, zero environmental loads are acting, or reinforcement corrosion resistance is infinite). In absence of a suitable model for reallife structures with a strong international consensus, service life is currently evaluated as the time to corrosion initiation so that to reach the limit state of reinforcement depassivation (i.e., the serviceability limit state (SLS) for carbonation-induced corrosion), similarly as in the Tuutti model [19]. In this work, the full-probabilistic fib model is used to evaluate the reliability of RAC carbonation resistance, taking into account, as significant parameters, aggregate replacement ratio and water/cement (w/c) ratio. Such approach is considered particularly appropriate when dealing with such kind of concretes, whose mechanical and transport properties (e.g., concrete compressive strength, porosity, and absorption) are affected by high uncertainty, associated with the heterogeneity of the original materials. Other than the above approach, some existing formulations provided in literature and generally applied to NAC are recalled, whose deterministic application is compared to the full-probabilistic one. As a novelty element, it must be underlined that the proposed approach allows us to account for varying concrete compositional characteristics in the evaluation of carbonation resistance reliability of RAC members. At this stage, experimental results collected from the literature have been used to characterize RAC durability under carbonation, considering both recycled aggregate replacement ratio and water/cement ratio.

\section{Existing Models for Carbonation Prediction}

Carbonation is a commonly diffused process in old RC structures, generally built without specific design rules against degradation. The atmospheric $\mathrm{CO}_{2}$ penetrates in the concrete cover, via the interconnected pores to the inner core, and it reacts with calcium hydroxide, which is a product from the hydration of calcium silicate compounds of the clinker. Hence, the $\mathrm{pH}$ value is reduced and calcium carbonate is formed:

$$
\mathrm{Ca}(\mathrm{OH})_{2}+\mathrm{CO}_{2} \longrightarrow \mathrm{CaCO}_{3}+\mathrm{H}_{2} \mathrm{O}
$$

In addition, $\mathrm{CO}_{2}$ could also react with the $\mathrm{C}-\mathrm{S}-\mathrm{H}$ network to form additional $\mathrm{CaCO}_{3}$ [20]. Carbonation requires the presence of water, which is responsible for the movement of hydrated cement products in the pore solution and allows the $\mathrm{CO}_{2}$ to dissolve and form carbonic acid. A large set of experimental studies have been performed to analyze the empirical influencing parameters of the process. As a result, cement type and content, w/c ratio, environmental conditions, and eventual precracking pattern presence are considered as relevant factors.

Several physical-based numerical models were developed in the literature [4-6], which generally couple heat, moisture, and $\mathrm{CO}_{2}$ transport mechanism with the chemical reaction reported in (1), neglecting $\mathrm{C}-\mathrm{S}-\mathrm{H}$ reaction with $\mathrm{CO}_{2}$ for the sake of simplicity. Nevertheless, these methods are much time consuming to be difficulty applied in real structure design and verification; thus empirical laws are currently used. Most of them are based on the 1-D diffusion transport model (Fick's 1st law of diffusion), where the diffusion coefficient $k$ is assumed to be a constant material property, depending also on $\mathrm{CO}_{2}$ concentration in the environment and concrete $\mathrm{CO}_{2}$ binding capacity. Hence, carbonation depth $x_{\mathrm{c}}$ can be estimated for each time instant $t$ :

$$
x_{\mathrm{c}}=k \cdot \sqrt{t} \text {. }
$$

Many authors directly adopted this formulation due to its simple form, finding varying values of $k$ for concretes with different $\mathrm{w} / \mathrm{c}$ ratios, compressive strength, and mineral additions [21]. Monteiro et al. [22] proposed that carbonation diffusion is related to the mean concrete compressive strength, based on more than 100 of empirical observations on real structures having up to 65 years old, according to the following equation:

$$
k=847 \cdot f_{\mathrm{cm}}^{-1.435} \text {. }
$$

Some codes adopt formulation based on Fick's 1st law of diffusion too, to estimate the performance of reinforced concrete exposed to carbonation, such as LNEC E-465 [23], 
taking into account also factors related to target service life, environmental exposure class, test conditions for the assessment of carbonation diffusion coefficient, curing time, and required reliability.

One of the most considered models for carbonation depth estimation is the one proposed by Papadakis et al. [24], valid for indoor and outdoor concrete sheltered from rain, and for constant values of available $\mathrm{CO}_{2}$ :

$$
x_{\mathrm{c}}=\left(\frac{2\left[\mathrm{CO}_{2}\right]^{0} \mathrm{D}_{\mathrm{e}, \mathrm{CO}_{2}}}{[\mathrm{CH}]+3[\mathrm{CSH}]} t\right)^{1 / 2} \text { with } \mathrm{RH} \geq 50 \%,
$$

where carbonation depth is given in $\mathrm{m},\left[\mathrm{CO}_{2}\right]^{0}$ is the molar concentration of ambient $\mathrm{CO}_{2}$ in $\mathrm{mol} / \mathrm{m}^{3}, D_{\mathrm{e}, \mathrm{CO}_{2}}$ is the effective diffusivity of $\mathrm{CO}_{2}$ in the concrete in $\mathrm{m}^{2} / \mathrm{y},[\mathrm{CH}]+$ $3[\mathrm{CSH}]$ is the total molar concentration of carbonatable constituents of concrete in $\mathrm{mol} / \mathrm{m}^{3}, t$ is the time in years, and $\mathrm{RH}$ is the relative humidity, considered as invariant in time. The molar concentration of ambient carbon can be assessed as

$$
\left[\mathrm{CO}_{2}\right]^{0}=42 y_{\mathrm{CO}_{2}} \cdot 10^{-6} \text {, }
$$

where $y_{\mathrm{CO}_{2}}$ is the ambient content of $\mathrm{CO}_{2}$ by volume (ppmv). The effective diffusivity of $\mathrm{CO}_{2}$ in concrete is

$$
D_{e, \mathrm{CO}_{2}}=51.8 \varepsilon_{\mathrm{p}}^{1.8}\left[1-\left(\frac{\mathrm{RH}}{100}\right)\right]^{2.2}
$$

where $\varepsilon_{\mathrm{p}}$ is the porosity of fully hydrated and carbonated cement paste, estimated as

$$
\varepsilon_{\mathrm{p}} \approx\left(\frac{\rho_{\mathrm{c}}}{\rho_{\mathrm{w}}}\right) \frac{(\mathrm{w} / \mathrm{c})-0.3}{1+\left(\rho_{\mathrm{c}} / \rho_{\mathrm{w}}\right)(\mathrm{w} / \mathrm{c})}
$$

Lastly, the total molar concentration of carbonatable concrete constituents can be estimated with

$$
[\mathrm{CH}]+3[\mathrm{CSH}] \approx \frac{33000}{1+\left(\rho_{\mathrm{c}} / \rho_{\mathrm{w}}\right)(\mathrm{w} / \mathrm{c})+\left(\rho_{\mathrm{c}} / \rho_{\mathrm{a}}\right)(\mathrm{a} / \mathrm{c})}
$$

In (7) and (8), $\rho_{\mathrm{c}}, \rho_{\mathrm{w}}$, and $\rho_{\mathrm{a}}$ are the densities of cement, water, and aggregates in $\mathrm{kg} / \mathrm{m}^{3}$, respectively, and $\mathrm{c}, \mathrm{w}$, and $\mathrm{a}$ are the contents of cement, water, and aggregates in $\mathrm{kg} / \mathrm{m}^{3}$, respectively.

When time dependency is required (i.e., taking into account varying carbon concentration in time as a consequence of environmental factors, e.g., global warming), the model proposed by Yoon et al. [25] can be adopted, where carbonation depth is obtained in $\mathrm{cm}$, and it is valid also for unsheltered outdoor environment:

$$
x_{\mathrm{c}}=\sqrt{\frac{2 D_{\mathrm{CO}_{2}}(t)}{a} C_{\mathrm{CO}_{2}}(t) \cdot t\left(\frac{t_{0}}{t}\right)^{n_{\mathrm{m}}}},
$$

where $C_{\mathrm{CO}_{2}}(t)$ is the time-dependent mass concentration of ambient $\mathrm{CO}_{2}\left(10^{-3} \cdot \mathrm{kg} / \mathrm{m}^{3}\right), t_{0}$ is the reference period (e.g., one year), $t$ is the time in years, $D_{\mathrm{CO}_{2}}(t)$ is the $\mathrm{CO}_{2}$ diffusion coefficient in concrete, estimated with (10), $a$ is the coefficient calculated with (11), and $n_{\mathrm{m}}$ is the age factor, which takes the value equal to 0 or 0.12 , for sheltered or unsheltered environments:

$$
\begin{aligned}
D_{\mathrm{CO}_{2}}(t) & =D_{1} t^{-n_{\mathrm{d}}}, \\
a & =0.75 C_{\mathrm{e}} C_{\mathrm{CaO}} \alpha_{\mathrm{H}} \frac{M_{\mathrm{CO}_{2}}}{M_{\mathrm{CaO}}},
\end{aligned}
$$

where $D_{1}$ is the carbon diffusion coefficient after one year, $n_{\mathrm{d}}$ is the age factor for $\mathrm{CO}_{2}$ diffusion coefficient, $C_{\mathrm{e}}$ is cement content $\left(\mathrm{kg} / \mathrm{m}^{3}\right), C_{\mathrm{CaO}}$ is $\mathrm{CaO}$ content in cement (approximately equal to $65 \%$ ), and $\alpha_{\mathrm{H}}$ is the degree of hydration, which can be assumed after 400 days equal to

$$
\alpha_{\mathrm{H}} \approx 1-e^{-3.38 \mathrm{w} / \mathrm{c}} \text {. }
$$

Temperature may be considered as a variable of the diffusion process too, as it affects the kinetic of the reaction. Approximately, it can be considered that moving from $20^{\circ} \mathrm{C}$ to $30^{\circ} \mathrm{C}$ leads to $30 \%$ increase of carbonation rate. Such effect can be computed through Arrhenius's law:

$$
f_{T}(T)=e^{E / R\left(\left(1 /\left(273+T_{\mathrm{REF}}\right)\right)-(1 /(273+T(t)))\right)},
$$

where $E$ is the activation energy of the diffusion process in $\mathrm{kJ} / \mathrm{mol}$, depending on the $\mathrm{w} / \mathrm{c}$ ratio, $R$ is the ideal gas constant, and $T_{\mathrm{REF}}$ is the reference temperature and $T(t)$ is the temperature at time $t$, both in ${ }^{\circ} \mathrm{C}$.

\section{3. fib Bulletin 34 Full-Probabilistic Carbonation Prediction}

Concerning full-probabilistic models, fib Bulletin 34 [18] proposed an empirical formulation based on 1-D Fick's 1st law of diffusion for carbonation diffusion in uncracked concrete, where several variables are considered, and which influence is derived from an extensive experimental campaign developed within the research projects DuraCrete [8] and DARTS [26]. According to this model, the probability of depassivation occurrence is defined as

$$
p_{\mathrm{dep}}=p\left\{a-x_{\mathrm{c}}\left(t_{\mathrm{SL}}\right)<0\right\} \text {, }
$$

where $a$ is the concrete cover in $\mathrm{mm}$ and $x_{\mathrm{c}}\left(t_{\mathrm{SL}}\right)$ is the carbonation depth in $\mathrm{mm}$ at the time instant $t_{\mathrm{SL}}$ in $\mathrm{y}$. Such probability should be less than $p_{0}$, which is the target failure probability, depending both on the exposure class (XC, XD, or XS, according to EN206) and on the reliability class adopted ( $\mathrm{RC} 1, \mathrm{RC} 2$, or $\mathrm{RC} 3$ ). The reliability class is identified univocally by the following consequence classes: CC1, CC2, and CC3 are adopted for structures characterized by, respectively, low, medium, and high consequences of loss of human life and financial, social, or environmental consequences. Residential, office buildings, and public buildings where consequences of failure can be considered as medium belong to CC2 class and thus should be verified for the RC2 class. In this case, the target failure probability $p_{0}$ that defines the triggering of steel depassivation is equal to $10^{-1}$, corresponding to a reliability index $\beta$ of 1.3 , which it might be increased in case of particularly aggressive environments. It is possible to rewrite (14), as the carbonation depth is estimated as 


$$
x_{\mathrm{c}}=\sqrt{2 \cdot k_{\mathrm{e}} \cdot k_{\mathrm{c}} \cdot\left(k_{\mathrm{t}} \cdot R_{\mathrm{ACC}, 0}^{-1}+\varepsilon_{\mathrm{t}}\right) \cdot C_{\mathrm{s}}} \cdot \sqrt{t} \cdot W(t),
$$

where $k_{\mathrm{e}}$ is the environmental function $(-), k_{\mathrm{c}}$ is the execution transfer parameter $(-), k_{\mathrm{t}}$ is a regression parameter $(-), R_{\mathrm{ACC}, 0}^{-1}$ is the inverse effective carbonation resistance of concrete in $\left(\mathrm{mm}^{2} / \mathrm{y}\right) /\left(\mathrm{kg} / \mathrm{m}^{3}\right), \varepsilon_{\mathrm{t}}$ is the error term $(-), C_{\mathrm{s}}$ is the carbon concentration in $\mathrm{kg} / \mathrm{m}^{3}$, and $W(t)$ is the weather function (-). The environmental function is expressed as

$$
k_{\mathrm{e}}=\left(\frac{1-\left(\mathrm{RH}_{\mathrm{real}} / 100\right)^{f_{\mathrm{e}}}}{1-\left(\mathrm{RH}_{\mathrm{ref}} / 100\right)^{f_{\mathrm{e}}}}\right)^{g_{\mathrm{e}}},
$$

where $\mathrm{RH}_{\text {real }}$ is the relative humidity of the carbonated layer (\%), which is considered as a random variable (r.v.) described by a right-skewed distribution (e.g., Beta or Weibull distribution), $\mathrm{RH}_{\text {ref }}$ is the reference relative humidity (\%) assumed as $65 \%$, and $f_{\mathrm{e}}$ and $g_{\mathrm{e}}$ are two exponents, assumed as 2.5 and 5.0 , respectively. The execution transfer parameter depends on the period of curing $t_{\mathrm{c}}$ with the following power law:

$$
k_{\mathrm{c}}=\left(\frac{t_{\mathrm{c}}}{7}\right)^{b_{\mathrm{c}}}
$$

where $b_{c}$ is the exponent, which is considered as a r.v. normally distributed with the mean value of -0.567 and standard deviation (s.d.) of 0.024. Regression parameter and error terms are test method factors, which were introduced in the formulation to transform the results gained from accelerated carbonation tests to represent natural carbonation condition. Indeed, experimental results carried out under the former condition are much more common than under the latter. Hence, $k_{\mathrm{t}}$ is considered as a r.v. with a normal distribution of mean value 1.25 and s.d. 0.35 ; similarly, $\varepsilon_{t}$ is a r.v. with the mean value of 315.5 and s.d. of 48. The inverse effective carbonation resistance of concrete refers to results obtained in accelerated carbonation tests, where carbonation depth is measured through a colorimetric test based on spraying an aqueous solution containing $1.0 \mathrm{~g} / \mathrm{l}$ of phenolphthalein on concrete surface. $R_{\mathrm{ACC}, 0}^{-1}$ is characterized by a normal distribution in natural concretes, whose mean value is that experimentally measured, and s.d. $=0.69 \cdot R_{\mathrm{ACC}, 0}^{-1}$. Carbon concentration represents instead the sum of the atmospheric $\mathrm{CO}_{2}$ concentration and the additional concentration due to potential presence of point emission sources. Particularly, atmospheric carbon concentration should account for the increasing trend of $\mathrm{CO}_{2}$ availability in atmosphere, and it can be estimated as a normally distributed r.v. with the mean value of 0.00082 and s.d. of 0.0001 . Concerning the weather function, it takes into account the environmental conditions affecting the RC structure, according to the following equation:

$$
W=\left(\frac{t_{0}}{t}\right)^{\left(p_{\mathrm{sR}} \cdot \mathrm{ToW}\right)^{b_{\mathrm{W}} / 2}}=\left(\frac{t_{0}}{t}\right)^{W},
$$

where $t_{0}$ is the time of reference, equal to $0.0767 ; p_{\mathrm{sR}}$ is the probability of driving rain on the element, varying between 0 and 1, respectively; for interior and exterior horizontal elements, ToW is the time of wetness, defined as the average number of rainy days per year (with the minimum
TABle 1: Coefficients of (19) for carbonation rate estimation in RACs.

\begin{tabular}{lccc}
\hline & $\alpha_{1}$ & $\beta_{1}$ & $R^{2}$ value \\
\hline$R=0 \%$ & 0.15 & 3.3 & 0.73 \\
$R=20 \%$ & 0.17 & 3.2 & 0.85 \\
$R=50 \%$ & 0.14 & 3.6 & 0.70 \\
$R=100 \%$ & 0.088 & 4.6 & 0.95 \\
\hline
\end{tabular}

${ }^{*} R=$ replacement ratio.

TABle 2: Coefficients of (22) and (23) for relative density and concrete compressive strength estimation at 28 days in RACs.

\begin{tabular}{lcccccc}
\hline & $\alpha_{2}$ & $\beta_{2}$ & $R^{2}$ value & $\alpha_{3}$ & $\beta_{3}$ & $R^{2}$ value \\
\hline$R=0 \%$ & 2.7 & 0.5 & 0.97 & 130 & -1.90 & 0.97 \\
$R=20 \%$ & 2.6 & 0.5 & 0.91 & 115 & -1.80 & 0.98 \\
$R=50 \%$ & 2.6 & 0.52 & 0.94 & 120 & -1.90 & 0.79 \\
$R=100 \%$ & 2.55 & 0.52 & 0.90 & 130 & -2.10 & 0.83 \\
\hline
\end{tabular}

${ }^{*} R=$ replacement ratio.

precipitation water of $2.5 \mathrm{~mm}$ ); and the exponent $b_{\mathrm{w}}$ is a r.v., normally distributed, with the mean of 0.446 and s.d. of 0.163 .

\section{Durability Design and Reliability Assessment}

4.1. Carbonation Resistance of RAC. Scientific literature commonly agrees highlighting that carbonation resistance is lowered when recycled aggregates are used [11], even with few discording results that might be due to other compositional influencing factors [17]. The magnitude of such influence depends on several factors, that is, replacement ratio, w/c ratio, aggregates size and quality, and type of admixtures used [27]. Particularly, some empirical formulations [27, 28] were developed in the literature aimed at estimating the carbonation coefficient of RAC. A relationship proposed by Thomas et al. [28] seems particularly suitable for this scope, being derived on a large set of experimental mixes, with varying w/c ratio, cement dosage, and replacement ratio, and subject to accelerated carbonation tests. Equation (19) allows us to calculate carbonation rate $k$ in $\mathrm{mm} /$ day $^{0.5}$ starting from the knowledge of the $\mathrm{w} / \mathrm{c}$ ratio:

$$
k=\alpha_{1} \cdot \exp \left(\beta_{1} \cdot \frac{\mathrm{w}}{\mathrm{c}}\right) \text {, }
$$

where parameters $\alpha_{1}$ and $\beta_{1}$ depend on coarse aggregate replacement ratio $R$ and are listed in Table 1, with the $R^{2}$ value. It is worth recalling that, however, with this approach, it is not possible to distinguish clearly how RA quality and composition affect RAC durability, but the results refer on generic RA from crushed concrete structures, complying with the requirements included in the standard EN 12620 [14].

4.2. Input Parameters and Limit State Function. Inverse effective carbonation resistance of concrete can be estimated from the knowledge of carbonation rate $k$, as obtained with the model proposed by Thomas et al. [28], through the calculation of the average carbonation depth:

$$
x_{\mathrm{c}}=\sqrt{2 \cdot\left(k_{\mathrm{t}} \cdot R_{\mathrm{ACC}, 0}^{-1}+\varepsilon_{\mathrm{t}}\right) \cdot C_{\mathrm{s}}} \cdot \sqrt{t}=k \cdot \sqrt{t} .
$$


TABLE 3: Input parameters.

\begin{tabular}{|c|c|c|c|c|}
\hline Principal variable & Secondary variable & Unit & Distribution & Values \\
\hline \multicolumn{5}{|c|}{ Concrete properties-for all the models } \\
\hline $\mathrm{w} / \mathrm{c}$ ratio & - & - & - & From 0.50 to 0.65 \\
\hline$R$ & - & $\%$ & - & From 0 to $100 \%$ \\
\hline$f_{c}$ & - & $\mathrm{MPa}$ & - & Evaluated with (23) \\
\hline \multicolumn{5}{|c|}{ fib Bulletin $34[18]$} \\
\hline$R_{A C C, 0}^{-1}$ & - & $\left(\mathrm{mm}^{2} / \mathrm{y}\right) /\left(\mathrm{kg} / \mathrm{m}^{3}\right)$ & Normal & $\mu$ (evaluated with (20)); $\sigma=0.69 \cdot R_{\mathrm{ACC}, 0}^{-1}$ \\
\hline$k^{A C C, 0}$ & - & $\mathrm{mm} /$ day $^{0.5}$ & - & Evaluated with (19), coefficients in Table 1 \\
\hline$k_{\mathrm{t}}$ & - & - & Normal & $\mu=1.25 ; \sigma=0.35$ \\
\hline$\varepsilon_{\mathrm{t}}$ & - & - & Normal & $\mu=315.5 ; \sigma=48$ \\
\hline & $t_{\mathrm{c}}$ & days & - & 3 \\
\hline$k_{\mathrm{c}}$ & $b_{\mathrm{c}}$ & - & Normal & $\mu=-0.567 ; \sigma=0.024$ \\
\hline \multirow{4}{*}{$k_{\mathrm{e}}$} & $\mathrm{RH}_{\text {real }}$ & $\%$ & Weibull & $a=80 ; \mathrm{b}=5$ \\
\hline & $\mathrm{RH}_{\text {ref }}$ & $\%$ & - & 65 \\
\hline & $g_{\mathrm{e}}$ & - & - & 2.5 \\
\hline & $f_{\mathrm{e}}$ & - & - & 5.0 \\
\hline$C_{\mathrm{s}}$ & - & $\mathrm{kg} / \mathrm{m}^{3}$ & Normal & $\mu=0.00082 ; \sigma=0.0001$ \\
\hline \multirow{4}{*}{$W(t)$} & $t_{0}$ & years & - & 0.0767 \\
\hline & $p_{\mathrm{sR}}$ & - & - & 0.1 \\
\hline & $b_{\mathrm{w}}$ & - & Normal & $\mu=0.446 ; \sigma=0.163$ \\
\hline & ToW & - & - & 0.246 \\
\hline $\mathrm{a}$ & - & $\mathrm{mm}$ & Normal & $\mu=30 ; \sigma=10$ \\
\hline \multicolumn{5}{|c|}{ Papadakis et al. model [24] } \\
\hline$\rho_{\mathrm{a}}$ (NAs) & - & $\mathrm{kg} / \mathrm{m}^{3}$ & - & 2700 \\
\hline$\rho_{\mathrm{a}}$ (RAs) & - & $\mathrm{kg} / \mathrm{m}^{3}$ & - & 2300 \\
\hline$\rho_{\mathrm{c}}$ & - & $\mathrm{kg} / \mathrm{m}^{3}$ & - & 3100 \\
\hline$\rho_{\mathrm{w}}$ & - & $\mathrm{kg} / \mathrm{m}^{3}$ & - & 1000 \\
\hline$\%$ coarse aggregates & - & - & - & 50 \\
\hline$\rho_{\text {concrete }}$ & - & $\mathrm{kg} / \mathrm{m}^{3}$ & - & Evaluated with (22) \\
\hline c & - & $\mathrm{kg} / \mathrm{m}^{3}$ & - & From 260 to 340 \\
\hline $\mathrm{w}$ & - & $\mathrm{kg} / \mathrm{m}^{3}$ & - & 170 \\
\hline $\mathrm{a}$ & - & $\mathrm{kg} / \mathrm{m}^{3}$ & - & $\rho_{\text {concrete }}-\mathrm{c}-\mathrm{w}$ \\
\hline$y_{\mathrm{CO}_{2}}$ & - & ppmv & - & 500 \\
\hline $\mathrm{RH}^{2}$ & - & $\%$ & - & 80 \\
\hline
\end{tabular}

Equation (20) derives from (15), where $k_{\mathrm{e}}, k_{\mathrm{c}}$, and $W(t)$ are equal to 1 in standard laboratory conditions used during the accelerated carbonation tests carried out by Thomas et al. [28]; $k_{\mathrm{t}}$ and $\varepsilon_{\mathrm{t}}$ refer to the accelerated test method and were already defined; and $C_{s}$ is the $\mathrm{CO}_{2}$ concentration during the experiment, equal to $2 \%$ in volume. Then, the s.d. value is assumed as $0.69 \cdot R_{\mathrm{ACC}, 0}^{-1}$, similarly as for NAC, because the same variability was observed in the experimental results obtained in [28], regardless of the aggregates replacement ratio. The following equation defines the limit state function to be solved, where $a$ is the concrete cover and $x_{\mathrm{c}}$ the carbonation depth, both in $\mathrm{mm}$ :

$$
Z=R-S=a-x_{\mathrm{c}}(t) \text {. }
$$

The reliability analysis is carried out for consequence class $\mathrm{CC} 2$, reliability class $\mathrm{RC} 2$, and the four carbonation classes $\mathrm{XC1}, \mathrm{XC} 2, \mathrm{XC} 3$, and $\mathrm{XC} 4$, which are used as indication to vary the $\mathrm{w} / \mathrm{c}$ ratio under the same environmental condition (considered as ordinary-few aggressive). For each of them, deemed-to-satisfy requirements (according to the Italian Code [29]) are considered to select the mean value of the concrete cover, which is taken as a r.v. with the Weibull distribution, with the average value of $30 \mathrm{~mm}$ and s.d. of $10 \mathrm{~mm}$.

Then, the analysis is implemented using Monte Carlo methodology, estimating the reliability index $\beta$ for the analyzed cases. The use of Monte Carlo methodology is considered as very attractive because the failure criterion is relatively easy to check, and for the analyzed case, the computational effort is very limited. For each r.v., a sample of 50000 values is generated, and simulation convergence has been subsequently verified observing a coefficient of variation (C.O.V.) for the probability of failure estimator less than $0.5 \%$, that means a higher accuracy with respect to the classical C.O.V. target value of $5 \%$.

Lastly, the average results obtained with the fullprobabilistic model are compared with the predictions of two deterministic models, namely, Papadakis et al. [24] and Monteiro et al. [22] formulations, already recalled in Section 2. To apply those models, it was necessary to estimate before concrete density and compressive strength at 28 days, which is obtained with the expressions proposed by Thomas et al. [28]:

$$
\begin{aligned}
\rho_{\text {concrete }} & =\left(\alpha_{2}-\beta_{2} \cdot \mathrm{w} / \mathrm{c}\right) \cdot 1000, \\
f_{\mathrm{c}} & =\alpha_{3} \cdot \exp \left(\beta_{3} \cdot \mathrm{w} / \mathrm{c}\right),
\end{aligned}
$$

where the coefficients $\alpha_{2}, \alpha_{3}$ and $\beta_{2}, \beta_{3}$ depend on the recycled coarse aggregate substitution ratio and are listed in Table 2 . In the same table, also the $R^{2}$ values of the above expressions are listed. 


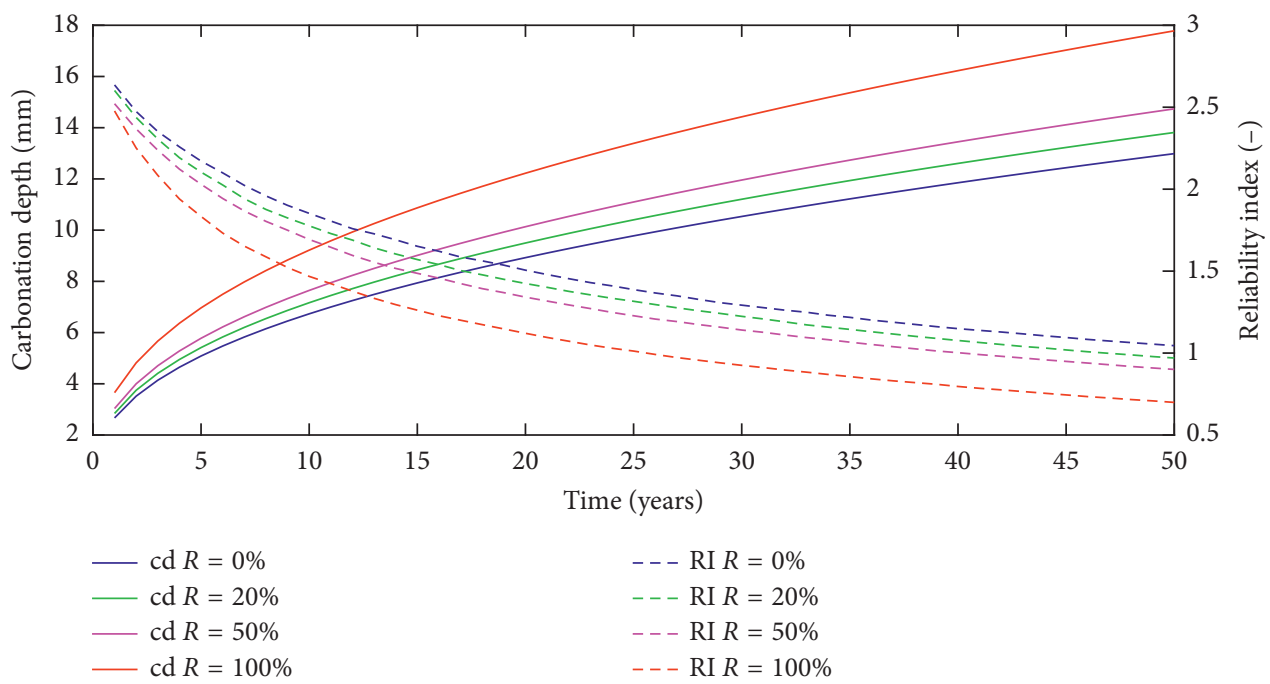

Figure 1: Carbonation depth (continuous line) and reliability index (dashed line) versus service life-XC1 exposure class: $\mathrm{w} / \mathrm{c}=0.65$.

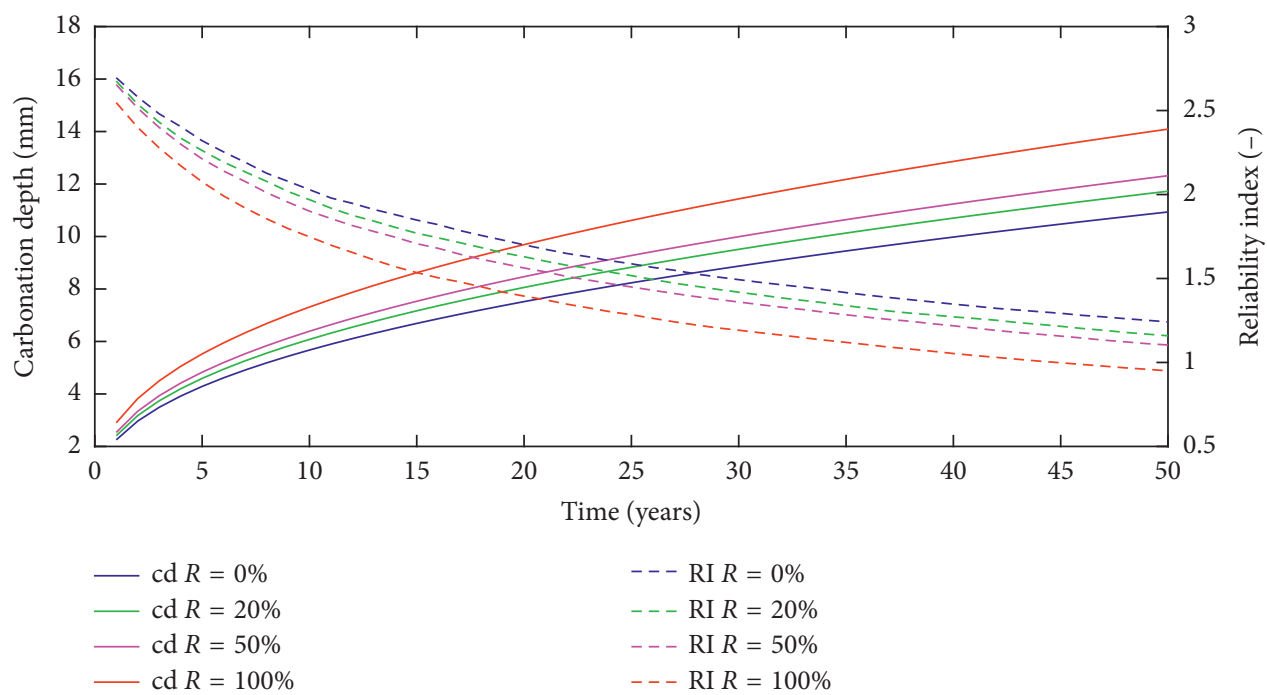

FIgure 2: Carbonation depth (continuous line) and reliability index (dashed line) versus service life-XC2 exposure class: $\mathrm{w} / \mathrm{c}=0.60$.

Table 3 summarizes instead the values and statistical distribution used to characterize the input parameters of both the full-probabilistic and deterministic models. It is worth to recall that environmental conditions $\left(\mathrm{CO}_{2}\right.$ concentration, $\mathrm{RH}$, and $T$ ) are considered invariant during time for all the models.

4.3. Results. Figures 1-4 show the time-dependent evolution of the reliability index (with dashed lines) for the four exposure classes XC1-XC4 (corresponding to decreasing w/c ratios in the mixes), when the replacement ratio varies between 0 and $100 \%$. In the same graph, the evolution of the average carbonation depth is plotted with continuous lines. It is worth noting that for all the cases, the same trend is observed, with higher level of reliability displayed by ordinary concretes $(R=0 \%)$ than that by recycled ones, with the worst behavior experienced by the full recycled concrete
( $R=100 \%)$. As the w/c ratio increases (hence, in case of structures employed in less aggressive environments, e.g., XC1), the reliability index $\beta$ shows a marked decreasing trend during time: this is due to the poor characteristics of the concrete, which are affected by a relevant increase in the inverse effective carbonation resistance $R_{\mathrm{ACC}, 0}^{-1}$. In this case, that is, when the w/c ratio is high, the impact of recycled aggregates presence in the mix is much more significant than when the $\mathrm{w} / \mathrm{c}$ ratio is low. Indeed, for the $\mathrm{w} / \mathrm{c}$ ratio $=0.65$, then $\beta$ varies between 0.69 and 1.05 , corresponding to failure probability of about $24 \%$ and $15 \%$; instead, for the w/c ratio $=0.50, \beta$ varies between 1.64 and 1.48 , corresponding to failure probability of about $5 \%$ and $7 \%$.

If reliability indexes are compared with target reliability (that indicates the triggering of steel depassivation), which should be in the range between 0.5 and 2.3 for most of the codes [30,31], and specifically higher than 1.3 for fib Bulletin 34 [18], it can be noted that, in some cases, $\beta$ is less than the 


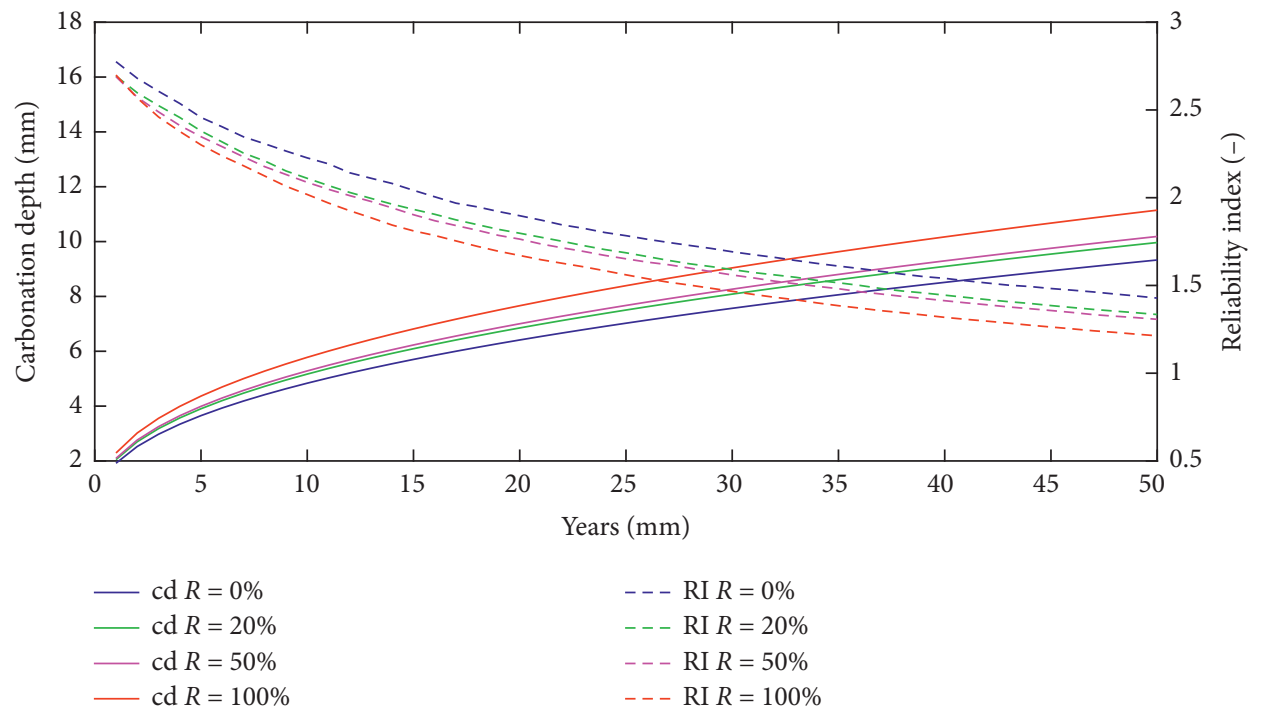

FIGURE 3: Carbonation depth (continuous line) and reliability index (dashed line) versus service life-XC3 exposure class: $\mathrm{w} / \mathrm{c}=0.55$.

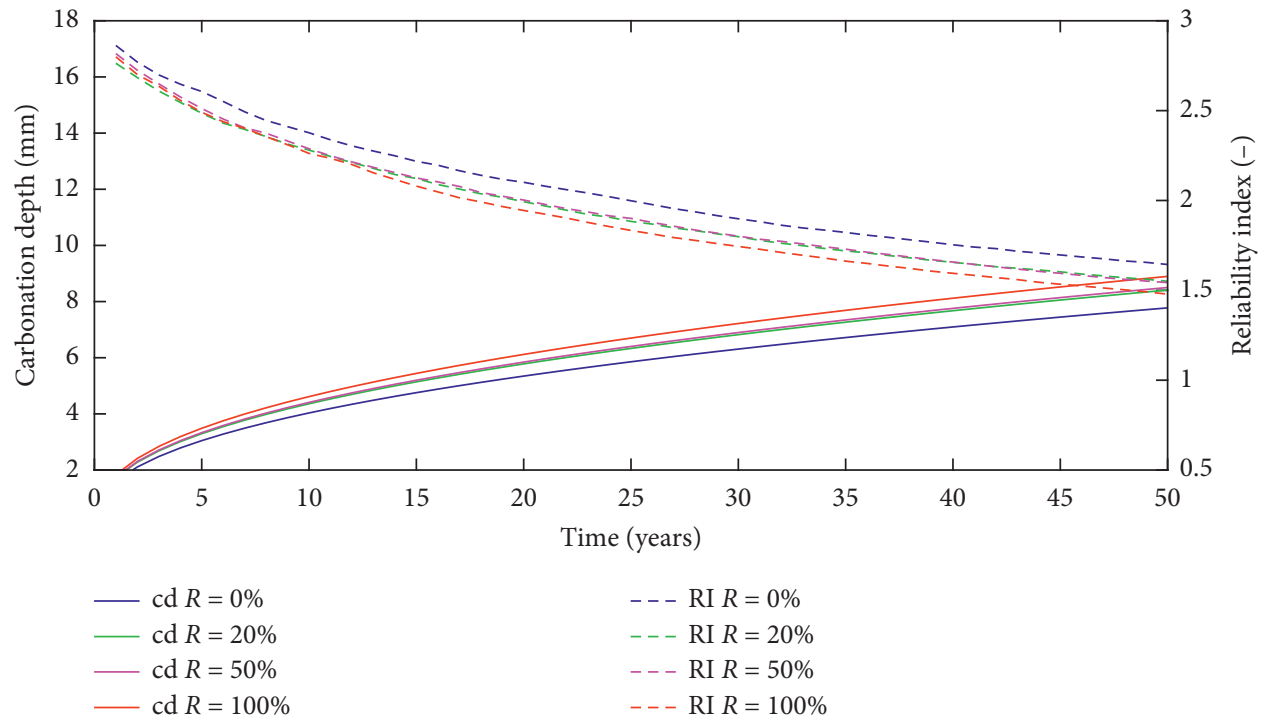

Figure 4: Carbonation depth (continuous line) and reliability index (dashed line) versus service life-XC4 exposure class: w/c $=0.50$.

recommended value at the required service life $\left(t_{\mathrm{SL}}=50\right.$ years). Particularly, for the two highest w/c ratios, failure probability is always greater than $p_{\mathrm{f}}=0.1$, regardless of the substitution ratio. Conversely, for the lowest w/c ratio, even if the substitution ratio reaches the overall quantity of coarse aggregates, the reliability does not decrease below 1.3.

Then, the average carbonation depth evaluated with the full-probabilistic model and with the deterministic formulations of Papadakis et al. [24] and Monteiro et al. [22] is plotted against time, highlighting a similar trend for all the models, as shown in Figures 5-8, for some relevant cases. As done above, varying replacement ratios and $\mathrm{w} / \mathrm{c}$ ratios were considered, the former ranging between 0.50 and 0.65 and the latter between $0 \%$ and $100 \%$. Results agree confirming a relevant influence of the w/c ratio on carbonation depth, higher than the replacement ratio, regardless of the model used to predict concrete deterioration. Additionally, the model proposed by Monteiro et al. [22] provides the highest estimates of carbonation depth, whereas the full-probabilistic approach provides in all the cases an intermediate estimate between the two deterministic ones. For the highest w/c ratio, and when no recycled aggregates are used, fib 34 prevision is very close to the Papadakis one.

It is possible to note also that the estimates of carbonation depth obtained with the full-probabilistic approach are more sensitive to the aggregates replacement ratio than the other models: on average, carbonation depth increases of more than $30 \%$ when coarse aggregates are fully replaced with recycled ones. Instead, when the Papadakis model is used, such difference is significantly reduced, because the model is only partially able to capture the influence of aggregates substitution through the aggregates density and proportions inside the mix. An intermediate prevision is given by the model proposed by Monteiro et al., which 


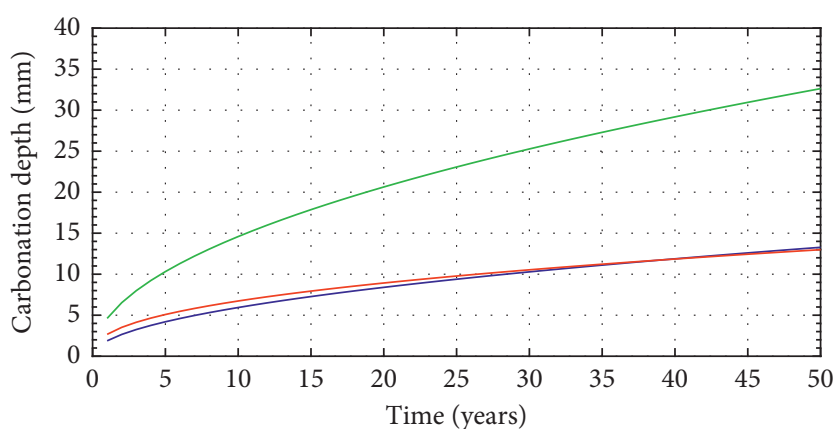

Papadakis et al.

Monteiro et al.

fib Bulletin 34

(a)

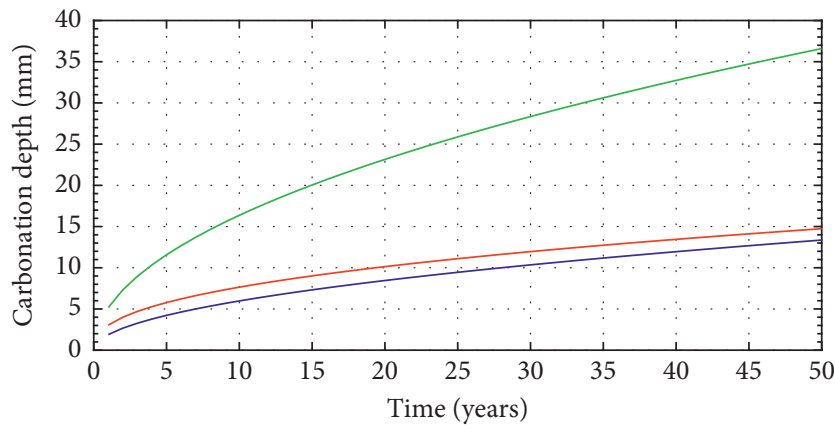

— Papadakis et al.

Monteiro et al.

fib Bulletin 34

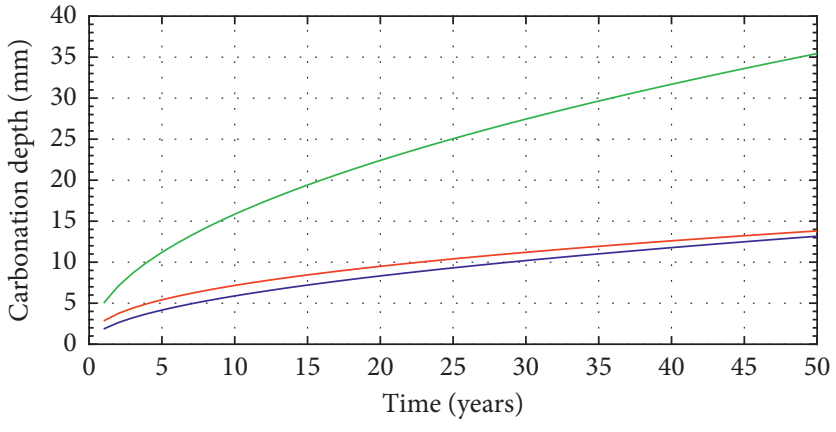

_ Papadakis et al.

- Monteiro et al.

_ fib Bulletin 34

(b)

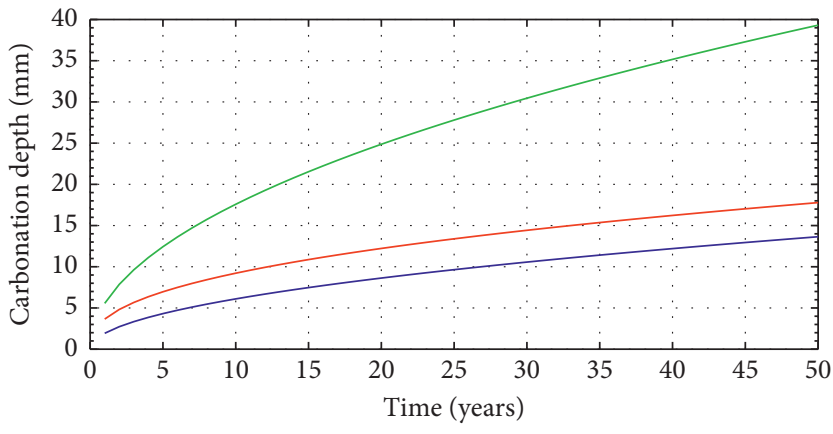

- Papadakis et al.

- Monteiro et al.

_ fib Bulletin 34

(c)

(d)

Figure 5: Comparison between models' prediction of carbonation depth versus service life: $\mathrm{XC1}$ exposure class: $\mathrm{w} / \mathrm{c}=0.65$. (a) $R=0 \%$; (b) $R=20 \%$; (c) $R=50 \%$; (d) $R=100 \%$.

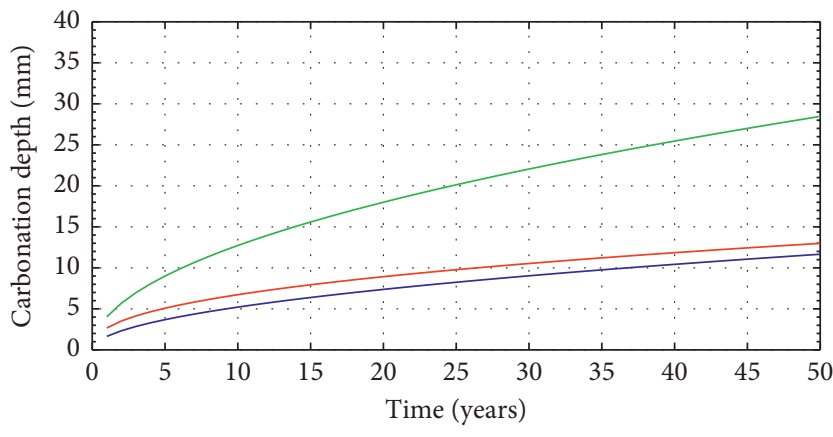

Papadakis et al.

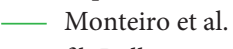

_ fib Bulletin 34

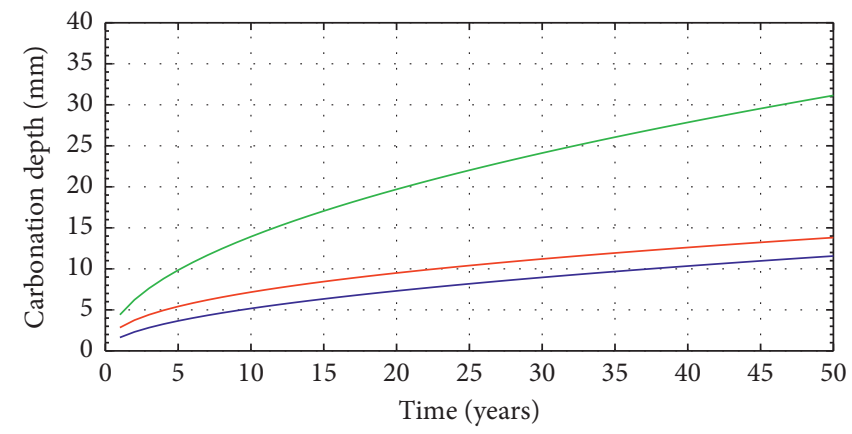

- Papadakis et al.

— Monteiro et al.

_ fib Bulletin 34

(a)

(b)

Figure 6: Continued. 


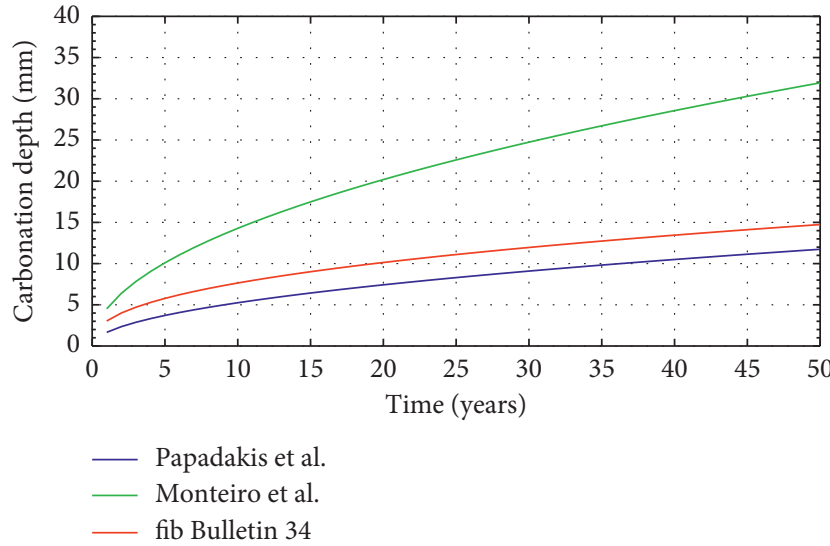

(c)

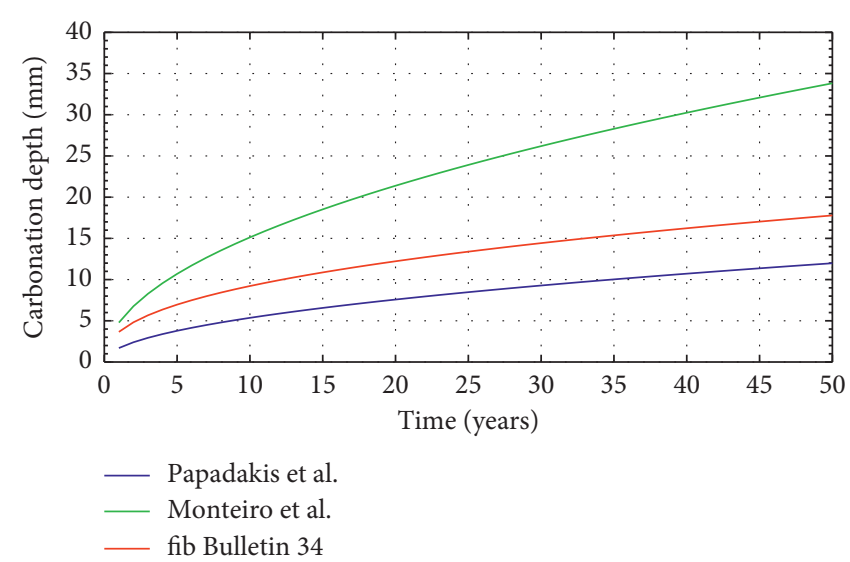

(d)

Figure 6: Comparison between models' prediction of carbonation depth versus service life: XC2 exposure class: w/c $=0.60$. $(a) R=0 \%$; (b) $R=20 \%$; (c) $R=50 \%$; (d) $R=100 \%$.

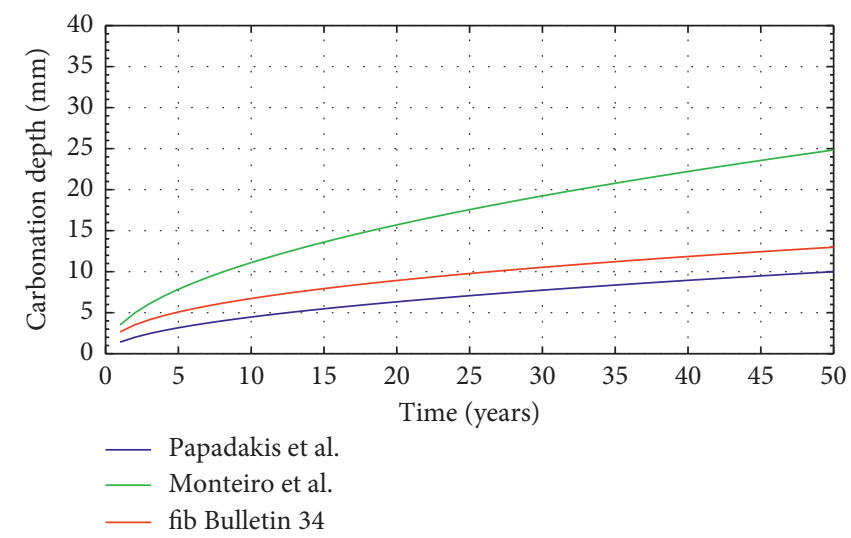

(a)

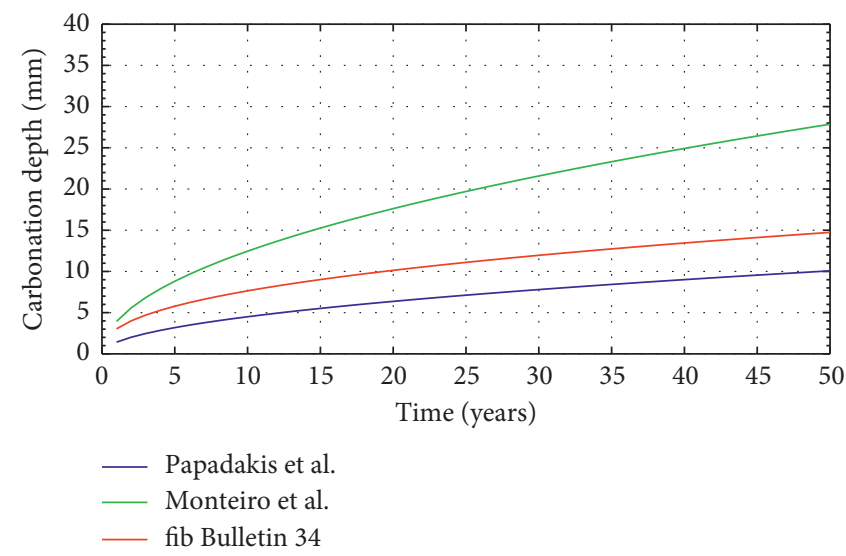

(c)

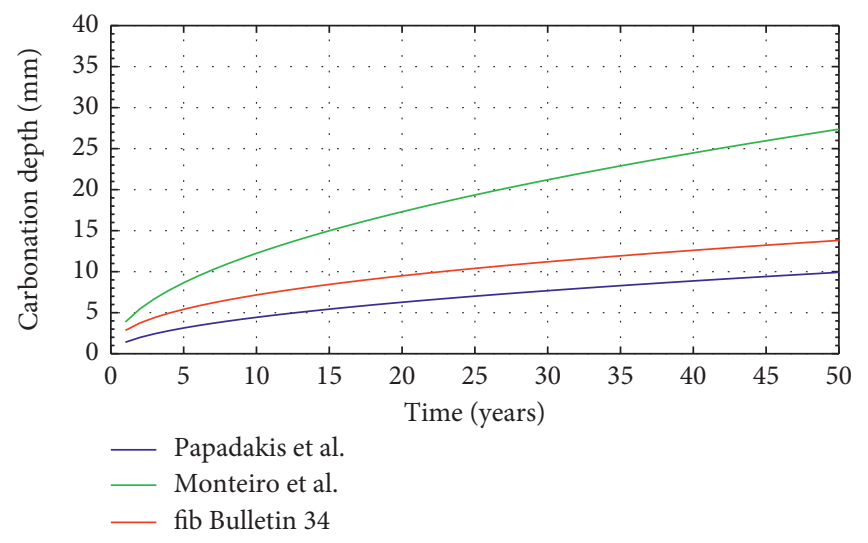

(b)

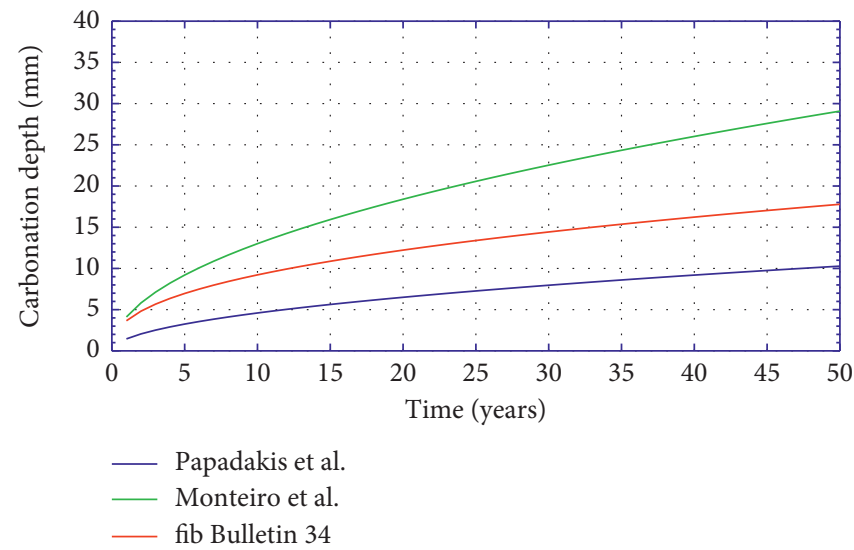

(d)

Figure 7: Comparison between models' prediction of carbonation depth versus service life: XC3 exposure class: w/c $=0.55$. (a) $R=0 \%$, (b) $R=20 \%$, (c) $R=50 \%$, (d) $R=100 \%$.

correlates carbonation rate with concrete compressive strength. In such way, carbonation depth increases of about $20 \%$ in average if coarse natural aggregates are fully replaced with recycled material.

\section{Conclusions}

This research work presents a reliability-based assessment of carbonation in recycled aggregate concretes, analyzing the 


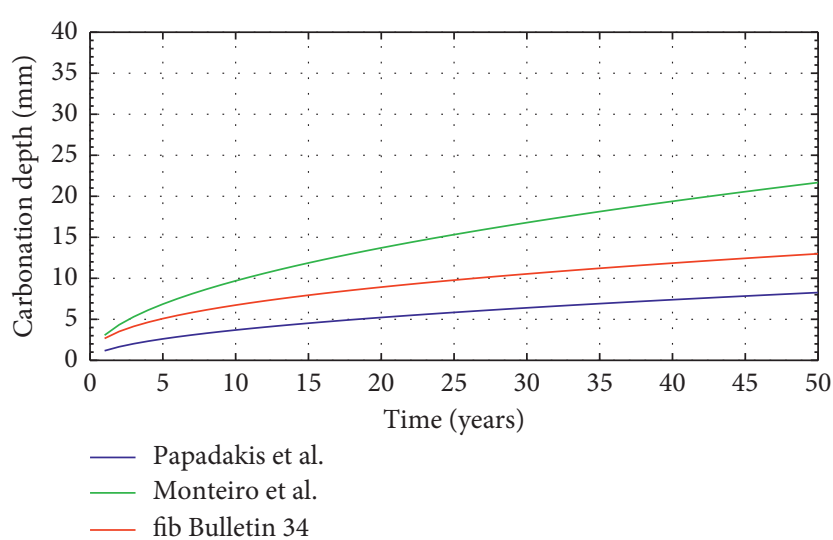

(a)

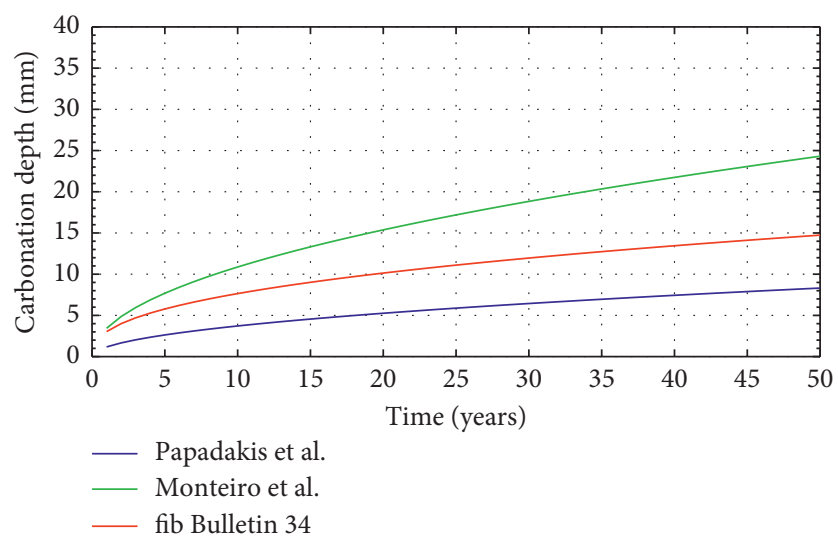

(c)

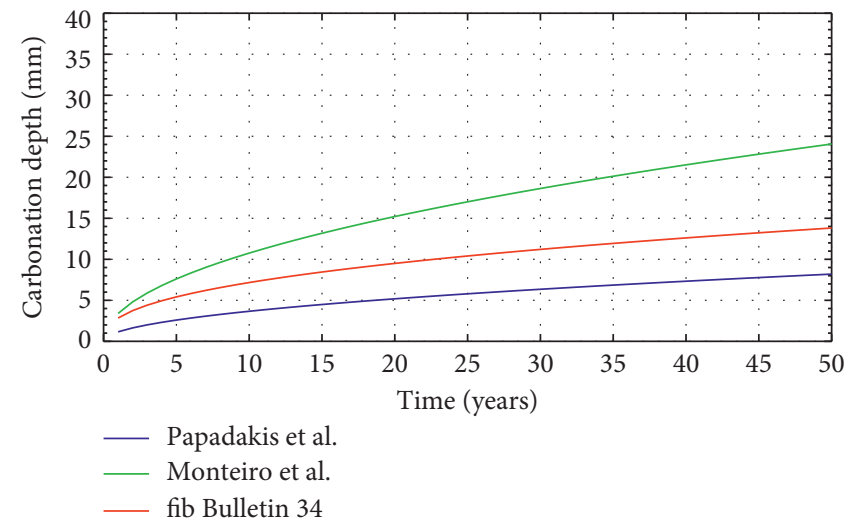

(b)

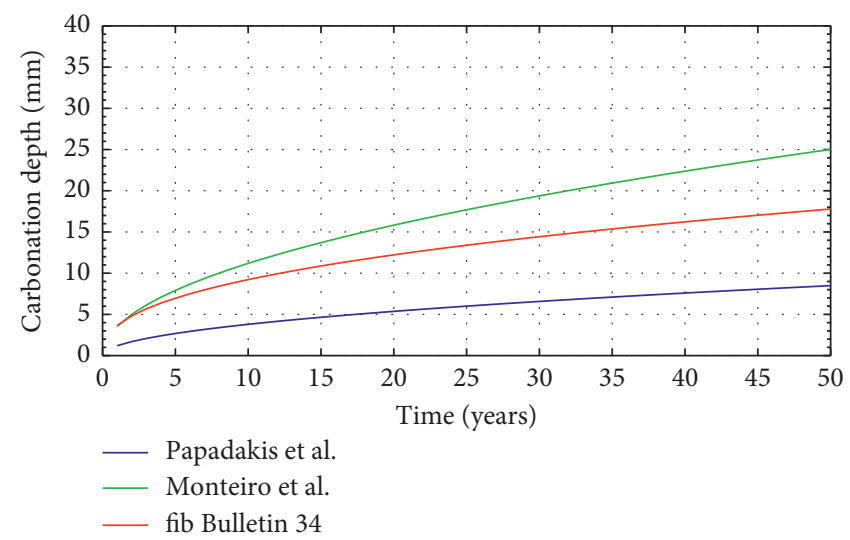

(d)

Figure 8: Comparison between models' prediction of carbonation depth versus service life: XC4 exposure class: w/c $=0.50 .(a) R=0 \%$; (b) $R=20 \%$; (c) $R=50 \%$; (d) $R=100 \%$.

effects of some compositional parameters on the probability that carbonation depth exceeds concrete cover during service life. At this stage, the influence of RA qualities (namely, water absorption, density, and old attached mortar content) on RAC durability is not included yet, and the analysis concerns coarse-recycled concrete aggregates, typically defined as "type A" RAs, according to $[13,14]$ and suitable to cast structural concretes. A full-probabilistic approach based on the fib Bulletin 34 model is considered in this work, whereas experimental carbonation rate in RAC is used, based on experimental results collected from the literature during accelerated carbonation tests. Results demonstrate that the water/cement ratio is the most influencing parameter on carbonation reliability of RAC, markedly higher than aggregates replacement ratio. Such result is observed regardless of the model used, even when deterministic approaches are considered, that is, when Papadakis et al. and Monteiro et al. formulations are applied. However, it is worth to recall that deterministic approaches might be not conservative in considering the effect of recycled aggregates replacement because they are less sensitive to this parameter than the full-probabilistic approach. Further research will aim at analyzing performance-based deemed-to-satisfy rules, specifically intended for RAC structures, subject to carbonation.

\section{Data Availability}

The analytical data used to support the findings of this study are available from the corresponding author upon request.

\section{Conflicts of Interest}

The authors declare that they have no conflicts of interest.

\section{References}

[1] M. A. Zanini, F. Faleschini, and C. Pellegrino, "Probabilistic seismic risk of aging bridge networks," Engineering Structures, vol. 136, pp. 219-232, 2017.

[2] M. G. Stewart, X. Wang, and M. N. Nguyen, "Climate change impact and risks of concrete infrastructure deterioration," Engineering Structures, vol. 33, no. 4, pp. 1326-1337, 2011.

[3] CEB, Durable Concrete Structures-Design Guide, Thomas Telford, London, UK, 1992.

[4] A. Steffens, D. Dinkler, and H. Ahrens, "Modeling carbonation for corrosion risk prediction of concrete structures," Cement and Concrete Research, vol. 32, no. 6, pp. 935-941, 2002.

[5] O. Burkan Isgor and A. Ghani Razaqpur, "Finite element modeling of coupled heat transfer, moisture transport and carbonation processes in concrete structures," Cement and Concrete Composites, vol. 26, no. 1, pp. 57-73, 2004. 
[6] B. Bary and A. Sellier, "Coupled moisture-carbon dioxide-calcium transfer model for carbonation of concrete," Cement and Concrete Research, vol. 34, no. 10, pp. 1859-187, 2004.

[7] A. V. Saetta, B. Schrefler, and R. V. Vitaliani, "The carbonation of concrete and the mechanism of moisture, heat and carbon dioxide flow through porous materials," Cement and Concrete Research, vol. 23, no. 4, pp. 761-772, 1993.

[8] DuraCrete, "Modelling of degradation: report R4-5," in EU Brite-EuRam III project DuraCrete (BE95-1347): Probabilistic Performance based Durability Design of Concrete Structures, DuraCrete, West Valley City, UT, USA, 1998.

[9] S. Medjigbodo, A. Z. Bendimerad, E. Rozière, and A. Loukili, "How do recycled concrete aggregates modify the shrinkage and self-healing properties?," Cement and Concrete Composites, vol. 86, pp. 72-86, 2018.

[10] N. Otsuki, S. I. Miyazato, and W. Yodsudjai, "Influence of recycled aggregate on interfacial transition zone, strength, chloride penetration and carbonation of concrete," Journal of Materials in Civil Engineering, vol. 15, no. 5, pp. 443-451, 2003.

[11] R. V. Silva, R. Neves, J. de Brito, and R. K. Dhir, "Carbonation behaviour of recycled aggregate concrete," Cement and Concrete Composites, vol. 62, pp. 22-32, 2015.

[12] M. Gomes and J. de Brito, "Structural concrete with incorporation of coarse recycled concrete and ceramic aggregates: durability performance," Materials and Structures, vol. 42, no. 5, pp. 663-675, 2009.

[13] EN 206: 2013, Concrete-Specification, Performance, Production and Conformity, Comité Europeen de Normalisation, Brussels, Belgium, 2013.

[14] EN 12620: 2008, Aggregates for Concrete, Comité Europeen de Normalisation, Brussels, Belgium, 2008.

[15] P. S. Lovato, E. Possan, D. C. C. D. Molin, A. B. Masuero, and J. L. D. Riberiro, "Modeling of mechanical properties and durability of recycled aggregate concretes," Construction and Building Materials, vol. 26, no. 1, pp. 437-447, 2012.

[16] S. C. Kou and C. S. Poon, "Long-term mechanical and durability properties of recycled aggregate concrete prepared with the incorporation of fly ash," Cement Concrete Composites, vol. 37, pp. 12-19, 2013.

[17] J. Z. Xiao, B. Lei, and C. Z. Zhang, "On carbonation behavior of recycled aggregate concrete," Science China Technological Sciences, vol. 55, no. 9, pp. 2609-2616, 2012.

[18] fib Bulletin 34, Model Code for Service Life Design, International Federation for Structural Concrete, Lausanne, Switzerland, 2006.

[19] K. Tuutti, Corrosion of Steel in Concrete, Swedish Cement and Concrete Research Institute, Stockholm, Sweden, 1982.

[20] M. A. Peter, A. Muntean, and M. Meier Bohm, "Competition of several carbonation reactions in concrete: a parametric study," Cement and Concrete Research, vol. 38, no. 12, pp. 1385-1393, 2008.

[21] M. Collepardi, S. Collepardi, J. J. Ogoumah Olagot, and F. Simonelli, "The influence of slag and fly ash on the carbonation of concretes," in Proceedings of the 8th CANMET/ ACI International Conference on Fly Ash, Silica Fume, Slag and Natural Pozzolans in Concrete, pp. 23-29, Las Vegas, NV, USA, May 2004.

[22] I. Monteiro, F. A. Branco, J. de Brito, and R. Neves, "Statistical analysis of the carbonation coefficient in open air concrete structures," Construction and Building Materials, vol. 29, pp. 263-269, 2012.
[23] LNEC E-465, Concrete Prescriptive Methodology to Estimate Concrete Properties to Achieve the Design Service Life under Environment Conditions XC or XS, in Portuguese, National Laboratory of Civil Engineering (LNEC), Lisbon, Portugal, 2005, in Portuguese.

[24] V. G. Papadakis, M. N. Fardis, and C. G. Vayenas, "Effect of composition, environmental factors and cement-lime mortar coating on concrete carbonation," Materials and Structures, vol. 25, no. 5, pp. 293-304, 1992.

[25] I.-S. Yoon, O. Çopuroglu, and K.-B. Park, "Effect of global climate change on carbonation progress of concrete," Atmospheric Environment, vol. 41, no. 34, pp. 7274-7285, 2007.

[26] DARTS, "Durable and reliable tunnel structures: deterioration modelling," Report 2-1, 2004.

[27] R. V. Silva, A. Silva, R. Neves, and J. de Brito, "Statistical modeling of carbonation in concrete incorporating recycled aggregates," Journal of Materials in Civil Engineering-ASCE, vol. 28, no. 1, article 04015082, 2016.

[28] C. Thomas, J. Setién, J. A. Polanco, P. Alaejos, and M. Sánchez de Juan, "Durability of recycled aggregate concrete," Construction and Building Materials, vol. 40, pp. 1054-1065, 2013.

[29] Norme Tecniche per le Costruzioni, 2008, Ministerial Decree, Rome, Italy, in Italian.

[30] EN 1990:2002, Eurocode 0-Basis of Structural Design, EN 206: 2013, Concrete - Specification, performance, production and conformity, Comité Europeen de Normalisation, Brussels, Belgium.

[31] ISO 2394:2015, General Principles on Reliability for Structures, International Organization for Standardization, Geneva, Switzerland. 


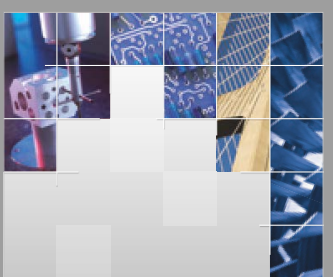

\section{Enfincering}
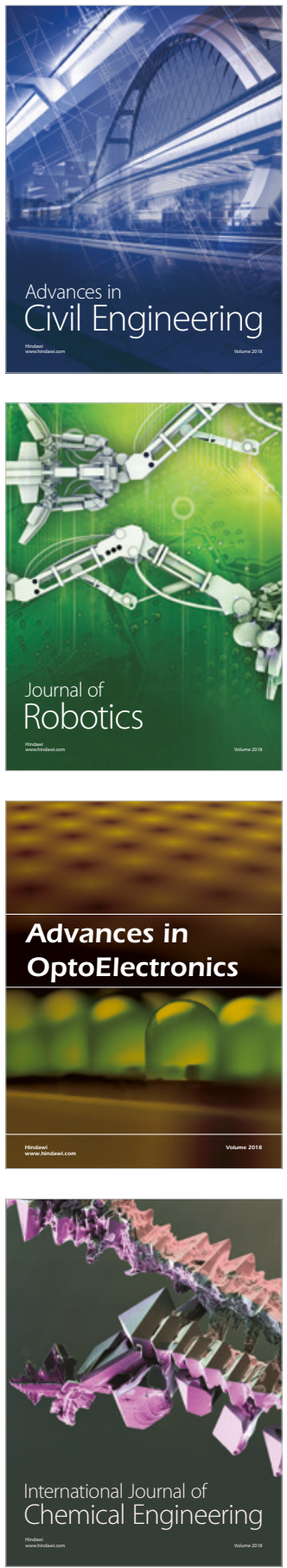

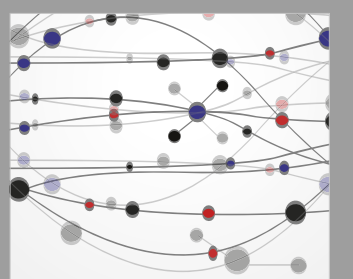

\section{Rotating \\ Machinery}

The Scientific World Journal

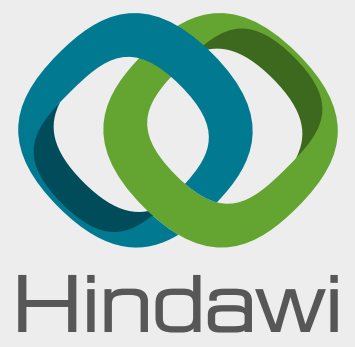

Submit your manuscripts at

www.hindawi.com
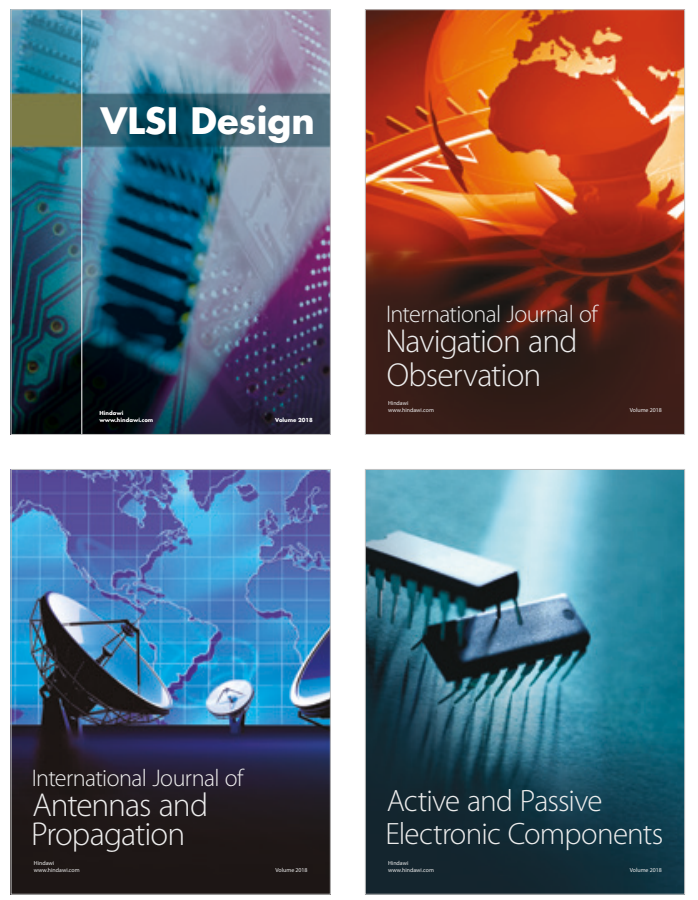
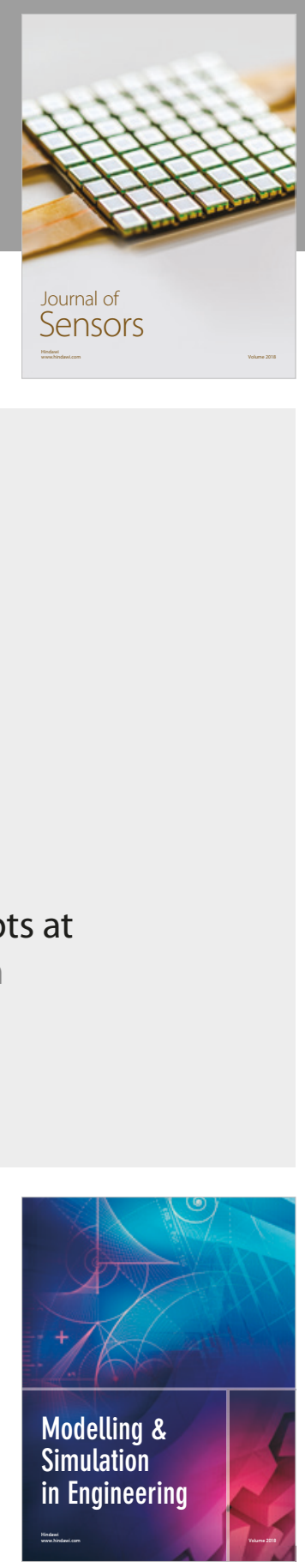

\section{Advances \\ Multimedia}
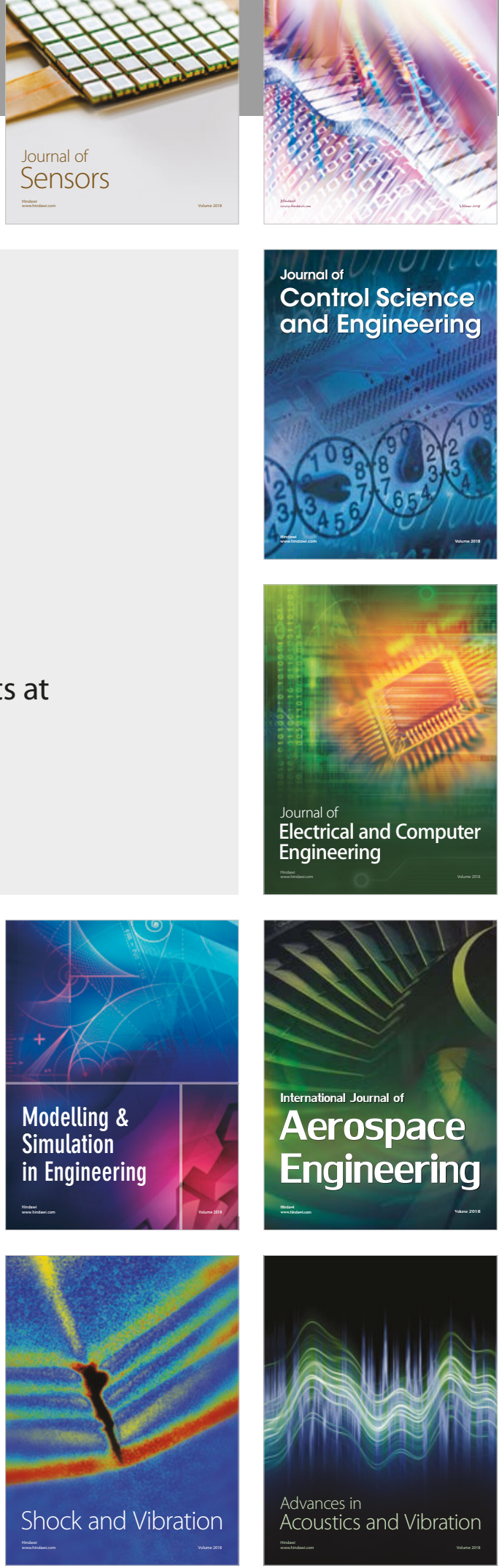